\begin{tabular}{|c|l|}
\hline Title & Photocatalytic activity of amorphous - anatase mixture of titanium(IV) oxide particles suspended in aqueous solutions \\
\hline Author(s) & Ohtani, Bunsho; Ogawa, Y oshimasa; Nishimoto, Seiichi \\
\hline Citation & $\begin{array}{l}\text { Journal of physical chemistry. B, 101(19), 3746-3752 } \\
\text { https://doi.org/10.1021/p962702+ }\end{array}$ \\
\hline Issue Date & 1997-05-08 \\
\hline Doc URL & http://hdl.handle.net/2115/52791 \\
\hline Type & article \\
\hline File Information & jp962702+.pdf \\
\hline
\end{tabular}

Instructions for use 


\title{
Photocatalytic Activity of Amorphous-Anatase Mixture of Titanium(IV) Oxide Particles Suspended in Aqueous Solutions
}

\author{
Bunsho Ohtani, *, ${ }^{\dagger}$ Yoshimasa Ogawa, and Sei-ichi Nishimoto \\ Department of Energy and Hydrocarbon Chemistry, Graduate School of Engineering, Kyoto University, \\ Kyoto 606-01, Japan
}

Received: August 30, 1996; In Final Form: January 30, $1997^{\circledR}$

\begin{abstract}
Titanium(IV) oxide $\left(\mathrm{TiO}_{2}\right)$ powders of various amorphous-anatase compositions were prepared by heat treatment $(573-1073 \mathrm{~K})$ of amorphous $\mathrm{TiO}_{2}$ in air and characterized by differential scanning calorimetry (DSC), powder X-ray diffraction (XRD), and BET surface area measurements. An exothermic peak at ca. $723 \mathrm{~K}$ in the DSC pattern was assigned to the crystallization of amorphous phase to anatase, and its heat was used to evaluate the weight fraction of amorphous phase. The fraction of anatase crystallites ( $f($ anatase)) was calculated as the remainder after the amorphous phase and contaminated water or organic residue. The XRD data showed that the size of anatase crystallites was slightly decreased but almost constant along with the increase in $f$ (anatase), being consistent with the small change in the BET surface area. These results suggest that each amorphous particle transforms into an anatase crystallite of similar size without sintering or crystal growth. The particles of mixture of amorphous and anatase were used for three kinds of photocatalytic reactions in deaerated aqueous suspensions: silver metal deposition with oxidation of 2-propanol by bare powders, and dehydrogenation of 2-propanol by ex situ and in situ platinized powders. For all the reactions, the photocatalytic activity of amorphous $\mathrm{TiO}_{2}$ was negligible, increased almost linearly with $f$ (anatase), and further improved by calcination of completely crystallized powder. The negligible activity of amorphous $\mathrm{TiO}_{2}$ was attributed to recombination of photoexcited electron and positive hole at defects located on the surface and in the bulk of particles.
\end{abstract}

\section{Introduction}

Semiconductor photocatalytic reaction has been investigated extensively, with applications focusing on solar energy conversion and storage, ${ }^{1,2}$ reductive fixation of carbon dioxide, ${ }^{3-8}$ organic synthesis, ${ }^{9-11}$ or mineralization and/or detoxification of organic compounds. ${ }^{12-14}$ Among semiconductors, titanium(IV) oxide $\left(\mathrm{TiO}_{2}\right)$ is one of the most popular and promising materials as a photocatalyst because it is stable in various solvents under photoirradiation, available commercially, and easy to prepare in the laboratory and has potent ability to induce various types of redox reactions. ${ }^{15}$ However, it has been also clarified that its photocatalytic activity strongly depends on its physical properties; a certain $\mathrm{TiO}_{2}$ powder showed no appreciable activity but another powder was quite active. There have been many articles reporting the correlation of photocatalytic activity with the physical properties of $\mathrm{TiO}_{2}$ powders, such as crystal structure, ${ }^{16-22}$ surface area, ${ }^{23}$ particle size,${ }^{24-27}$ surface hydroxyls, ${ }^{28-30}$ and so on. It is believed by most researchers in this field that the crystal structure (anatase, rutile, or brookite) is the most primitive and essential property to predict the photocatalytic activity, e.g., anatase, but not rutile, crystallites have relatively high photocatalytic activity. ${ }^{31,32}$ On the other hand, few papers have revealed the photocatalytic activity of amorphous $\mathrm{TiO}_{2}$; to the best of our knowledge, only one paper reported the negligible activity of amorphous $\mathrm{TiO}_{2}$ (same as that used in this study) by comparison with commercial crystalline $\mathrm{TiO}_{2}$ catalysts, but no interpretation for such behavior was given. ${ }^{27}$ Although a few reports ${ }^{33-35}$ described the photocatalytic activity of less (or negligibly) crystallized $\mathrm{TiO}_{2}$ particles, as amorphous $\mathrm{TiO}_{2}$, prepared by hydrolytic precipita-

\footnotetext{
* Author to whom correspondence should be addressed.

$\dagger$ Present address: Division of Chemistry, Graduate School of Science, Hokkaido University, Sapporo 060, Japan.

${ }^{\otimes}$ Abstract published in Advance ACS Abstracts, April 15, 1997.
}

tion from titanium(IV) alkoxides or halides, the particles may consist of, presumably, titanium(IV) hydroxide $\left(\mathrm{Ti}(\mathrm{OH})_{4}\right)$ or oxyhydroxide $\left(\mathrm{TiO}(\mathrm{OH})_{2}\right)$ or, in another expression, hydrated $\mathrm{TiO}_{2}\left(\mathrm{TiO}_{2} \cdot 2 \mathrm{H}_{2} \mathrm{O}\right.$ and $\left.\mathrm{TiO}_{2} \cdot \mathrm{H}_{2} \mathrm{O}\right)$.

In a series of studies on $\mathrm{TiO}_{2}$ photocatalytic reactions, ${ }^{23,29,36-39}$ we have shown that the overall kinetics depend on both amount of substrate(s) adsorbed on the surface to be reduced or oxidized by photoexcited electron $\left(\mathrm{e}^{-}\right)$or positive hole $\left(\mathrm{h}^{+}\right)$, respectively, and rate of geminate recombination of $\mathrm{e}^{-}$and $\mathrm{h}^{+}$. To obtain highly active $\mathrm{TiO}_{2}$ photocatalyst, therefore, it is necessary to give simultaneously a couple of properties, generally of contradiction, to the powders; large surface area to adsorb substrates and high crystallinity (or lesser surface and bulk defects) to diminish the $\mathrm{e}^{-}-\mathrm{h}^{+}$recombination. This hypothesis has been supported by the ultra-highly active $\mathrm{TiO}_{2}$ photocatalyst prepared by a newly developed method, hydrothermal crystallization in organic media (HyCOM) ${ }^{40,41}$ and thermal decomposition of titanium(IV) alkoxide (TD). ${ }^{42}$ The design and development of polycrystalline $\mathrm{TiO}_{2}$ photocatalysts are in progress along this line. Our research interest, then, focused on photocatalytic activity of amorphous, not crystalline, semiconductor particles. In this paper, the results of investigation on mixture of amorphous and anatase $\mathrm{TiO}_{2}$ powders are described and discussed.

\section{Experimental Section}

Materials. Amorphous $\mathrm{TiO}_{2}$ (type UF-IT-S) was supplied from Idemitsu Kosan Co., Ltd., as a flocculent white powder. A 5-10 g portion of this powder was calcined in air at various temperature $(573-1073 \mathrm{~K})$ and duration $(1-3 \mathrm{~h})$ in an electric furnace equipped with a time-programmed temperature controller. A commercial anatase $\mathrm{TiO}_{2}$ sample was supplied from Merck and used without pretreatment. Ex situ loading of platinum (Pt; 2 wt \%) on the $\mathrm{TiO}_{2}$ powders was achieved as 
follows. To an aqueous suspension of the powder was added dropwise an aqueous solution of chloroplatinic acid; the mixture was stirred thoroughly and then evaporated to dryness. The resulting pale yellow powder was heat-treated under hydrogen $\left(\mathrm{H}_{2}\right)$ stream at $453 \mathrm{~K}$ for $4 \mathrm{~h}$ in an electric furnace to obtain gray or grayish white powder of $\mathrm{TiO}_{2}-\mathrm{Pt}$.

The other chemicals used in this study were purchased from Wako Pure Chemical or Nacarai Tesque in the highest available grades. Ion-exchanged water prepared with a Corning MegaPure System MP-190 (>16 M $\Omega \mathrm{cm})$ was used to make the aqueous solutions throughout this study.

Characterization of $\mathrm{TiO}_{2}$ Powders. Differential scanning calorimetry was performed with a Shimadzu DSC-50 calorimeter under nitrogen $\left(\mathrm{N}_{2}\right)$ atmosphere. An ca. $2 \mathrm{mg}$ portion of sample powder was packed in an aluminum cell and set in the calorimeter. The calorimeter measured the heat flux from the sample with a unit of $\mathrm{mJ} \mathrm{s}^{-1} \mathrm{mg}^{-1}$. The rate of heating was 20 $\mathrm{K} \mathrm{s}^{-1}$. Therefore, the vertical axis of the results shown in Figure 1 had a dimension of $\mathrm{mJ} \mathrm{mg}^{-1} \mathrm{~K}^{-1}$ and the heat of crystallization could be calculated from the peak area in the unit of $\mathrm{mJ}$ $\mathrm{mg}^{-1}$. X-ray diffraction (XRD) pattern was recorded on a Rigaku Geigerflex 2013 diffractometer $(\mathrm{Cu} \mathrm{K \alpha}$, Ni filter, 35 $\mathrm{kV}, 20 \mathrm{~mA}$ ) at a scanning rate of $1 \mathrm{deg} \mathrm{min}^{-1}$. To prepare the XRD calibration curve (Figure 3), a commercial anatase $\mathrm{TiO}_{2}$ (Merck) was mixed with the original amorphous $\mathrm{TiO}_{2}$ with different weight ratio and $\mathrm{CaCO}_{3}$ corresponding to $20 \mathrm{wt} \%$ of the mixture was added. The details of XRD measurement were reported previously. ${ }^{20}$ The specific surface area of $\mathrm{TiO}_{2}$ samples was determined from $\mathrm{N}_{2}$ adsorption at $77 \mathrm{~K}$ on the basis of the BET equation by using a glass apparatus for constant-volume adsorption measurement equipped with an oil diffusion pump and an MKS Baratron type $122 \mathrm{~A}$ capacitance manometer. To minimize the change in physical properties of $\mathrm{TiO}_{2}$ samples, a drying process prior to this surface-area measurement was operated at $383 \mathrm{~K}$ under reduced pressure. Reflection spectra of powders in ultraviolet and visible region were recorded on a Hitachi U-4000 spectrophotometer. The powder samples are loaded in a cell equipped with a quartz window and reflectance was measured with a reference spectrum with barium sulfate. Reflectance $\left(R / R_{0}\right)$ was normalized at $500 \mathrm{~nm}$ to be 1 .

Photoirradiation and Product Analyses. (A) Photocatalytic reaction in an acidified silver sulfate $\left(\mathrm{Ag}_{2} \mathrm{SO}_{4}\right)$-2-propanol solution: bare $\mathrm{TiO}_{2}(50 \mathrm{mg})$ was suspended in an aqueous solution of $\mathrm{Ag}_{2} \mathrm{SO}_{4}$ (25 mmol dm$\left.{ }^{-3}, 5.0 \mathrm{~cm}^{3}\right)$ containing 2-propanol (500 $\mu \mathrm{mol})$. The $\mathrm{pH}$ of the solution was adjusted to 2.25 with sulfuric acid. (B) Photocatalytic reaction in an acidified potassium sulfate $\left(\mathrm{K}_{2} \mathrm{SO}_{4}\right)$-2-propanol solution: $\mathrm{K}_{2} \mathrm{SO}_{4}$ and ex situ deposited $\mathrm{TiO}_{2}-\mathrm{Pt}(2 \mathrm{wt} \%)$ were used instead of $\mathrm{Ag}_{2} \mathrm{SO}_{4}$ and bare $\mathrm{TiO}_{2}$ in system (A), respectively. The $\mathrm{pH}$ of the $\mathrm{K}_{2} \mathrm{SO}_{4}$ solution was adjusted to 2.25 also in this case. (C) Photocatalytic reaction in an aqueous 2-propanol solution: bare $\mathrm{TiO}_{2}(50$ $\mathrm{mg}$ ) was suspended in an aqueous solution $\left(5.0 \mathrm{~cm}^{3} ; \mathrm{pH}\right.$ was not adjusted) of 2-propanol $(500 \mu \mathrm{mol})$ and $\mathrm{H}_{2} \mathrm{PtCl}_{6}$ to be deposited as Pt ( 2 wt \%) during the photoirradiation. All the reactions were carried out under Ar with magnetic stirring (1000 $\mathrm{rpm})$. Temperature of the suspension was kept at $298 \pm 0.5 \mathrm{~K}$ in a thermostated water bath. Light of wavelength at $>300$ nm from a high-pressure mercury arc (Eiko-sha 400) passed through a cylindrical Pyrex glass filter and a reaction vessel. Gaseous products, such as $\mathrm{H}_{2}$ and oxygen $\left(\mathrm{O}_{2}\right)$, and liquid-phase products, such as acetone, were analyzed by gas chromatography (GC). ${ }^{20,43,44}$ Silver metal (Ag) deposited was analyzed by atomic absorption spectroscopy. ${ }^{37}$

Reduced species of $\mathrm{TiO}_{2}, \mathrm{Ti}^{3+}$, was measured quantitatively with methyl viologen $\left(\mathrm{MV}^{2+}\right.$, Wako) as follows. Bare $\mathrm{TiO}_{2}$

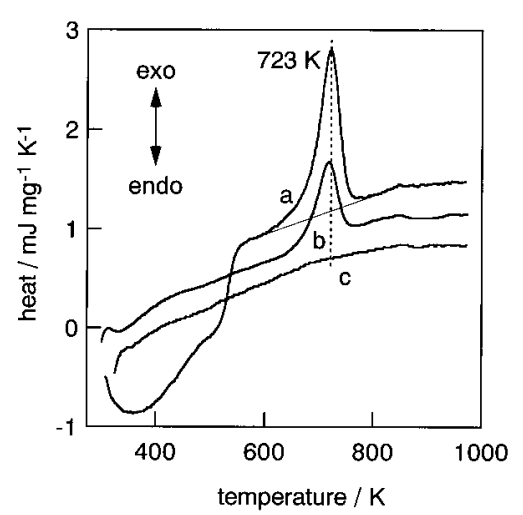

Figure 1. Representative DSC pattern of amorphous - anatase mixture of $\mathrm{TiO}_{2}$ powders: (a) as-received amorphous, (b) mixture ( $f$ (anatase) ca. 0.5) prepared from a by heat treatment $(573 \mathrm{~K}, 2 \mathrm{~h})$, and (c) remeasuring of a. Patterns were translated for clarity along the vertical axis.

was suspended in an aqueous 2-propanol solution and irradiated without $\mathrm{H}_{2} \mathrm{PtCl}_{6}$ under $\mathrm{Ar}$ at $298 \mathrm{~K}$ for $3 \mathrm{~h}$. To the photoirradiated reaction mixture was added a deaerated aqueous solution of $\mathrm{MV}^{2+}\left(0.5 \mathrm{mmol}, 0.5 \mathrm{~cm}^{3}\right)$. The resulting pale blue suspension containing reduced form of $\mathrm{MV}^{2+}, \mathrm{MV}^{\bullet+}$, was filtered and the supernatant solution was loaded in a sealable quartz cell (light path length $1 \mathrm{~mm}$ ) in an $\mathrm{N}_{2}$-purged vacuum glovebox. From the absorbance of solution at $602 \mathrm{~nm}$ (a Shimadzu MP1000 spectrophotometer) and reported extinction coefficient of $\mathrm{MV}^{\bullet+}\left(13700 \mathrm{~mol}^{-1} \mathrm{dm}^{3} \mathrm{~cm}^{-1}\right.$ at $\left.602 \mathrm{~nm}\right),{ }^{45}$ the molar amount of $\mathrm{Ti}^{3+}$ was estimated on the assumption that equimolar amounts of $\mathrm{Ti}^{3+}$ and $\mathrm{MV}^{2+}$ react to produce $\mathrm{MV}^{\bullet+}$.

\section{Results and Discussion}

Characterization of Amorphous-Anatase Mixture. Figure 1 is a representative DSC pattern of $\mathrm{TiO}_{2}$ samples. A characteristic exothermic peak was observed at ca. $723 \mathrm{~K}$ (curve a). An endothermic part below ca. $550 \mathrm{~K}$ was attributed to liberation or decomposition of water and/or organic residue, since it disappeared in the pattern of heat-treated $(573 \mathrm{~K}, 2 \mathrm{~h})$ sample (curve b). The as-received powder (giving no XRD peak of anatase crystallite, as described later) gave almost constant heat at ca. $723 \mathrm{~K}$ in several repeated measurements. This exothermic peak is attributable to crystallization of amorphous $\mathrm{TiO}_{2}$ to anatase crystallites since similar exothermic peak at $743 \mathrm{~K}$ has been also observed in differential thermal analysis under atmospheric conditions. ${ }^{46}$ The fact that decrease in the sample weight was seen at elevating temperature up to $573 \mathrm{~K}$ and thereafter it negligibly changed suggests that the exothermic peak is independent of the dehydration or decomposition of organic residue which must be accompanied by the change in weight. The heat of the crystallization was determined from the average of peak area in the several measurements to be 217 $\mathrm{J} \mathrm{g}^{-1}\left(4.1 \mathrm{kcal} \mathrm{mol}^{-1}\right)$, which is in the same order of magnitude of transformation of anatase into rutile, ${ }^{47} 392 \mathrm{~J} \mathrm{~g}^{-1}(7.5 \mathrm{kcal}$ $\mathrm{mol}^{-1}$ ), or amorphous germanium to its crystal, ${ }^{48} 158-178 \mathrm{~J}$ $\mathrm{g}^{-1}\left(2.8-3.1 \mathrm{kcal} \mathrm{mol}^{-1}\right)$. This heat of crystallization was used as a standard to determine the weight fraction of amorphous $\mathrm{TiO}_{2}$ (f(amorphous)), and that of anatase (f(anatase)) was estimated by an equation

$$
f(\text { anatase })=1-f(\text { amorphous })-f(\text { water })
$$

where $f$ (water) is weight fraction of water or organic residue in the sample and evaluated from the decrease in weight after DSC measurements. Actually, $f$ (water) was smaller than 0.04 for heat-treated samples and 0.08 for the as-received amorphous powder. 


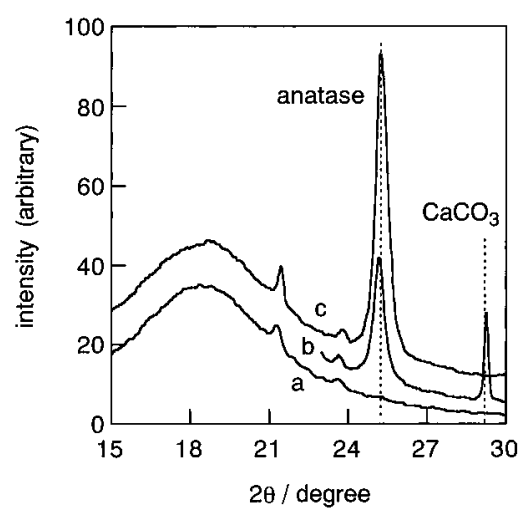

Figure 2. Representative XRD pattern of amorphous-anatase mixture of $\mathrm{TiO}_{2}$ powders: (a) as-received amorphous, (b) mixture ( $f$ (anatase) ca. 0.3 ), and (c) completely crystallized anatase. A broad peak at $2 \theta$ $=19^{\circ}$ and small peaks at $21^{\circ}$ and $23.5^{\circ}$ are caused by vaseline used to fix the powders on an XRD sample holder. Sample b contained $20 \mathrm{wt}$ $\%$ of $\mathrm{CaCO}_{3}$ as an internal standard.

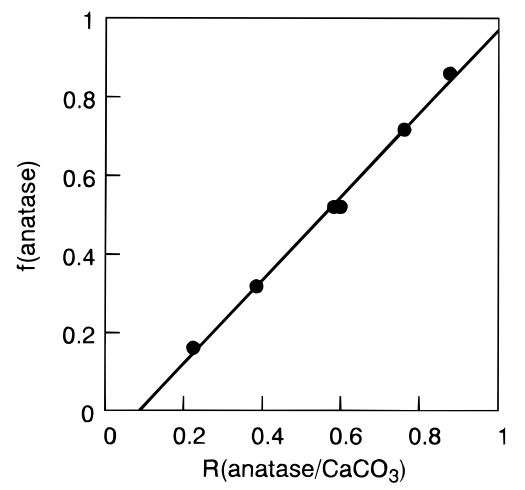

Figure 3. Calibration curve for anatase fraction as a function of peak intensity ratio of anatase $\mathrm{TiO}_{2}$ and $\mathrm{CaCO}_{3}$ as an internal standard. Merck $\mathrm{TiO}_{2}$ (anatase) was used as standard anatase sample.

Along with the decrease in amorphous fraction in the $\mathrm{TiO}_{2}$ samples, the XRD peak at $25.4^{\circ}$ assigned to anatase crystallite, increased (Figure 2). Before the calcination, no characteristic peak could be seen, showing that the as-received powder consisted of amorphous $\mathrm{TiO}_{2}$. Under the present calcination conditions (temperature $<1073 \mathrm{~K}$ ), formation of rutile or brookite crystallites could not be observed. The content of anatase crystallites could be also evaluated from the ratio of peak area between the peaks of anatase and an internal standard, calcium carbonate $\left(\mathrm{CaCO}_{3}\right.$; Wako, $\left.20 \mathrm{wt} \%\right) .{ }^{18}$ A calibration line was drawn with the mixture of a commercial anatase $\mathrm{TiO}_{2}$ (Merck) and $\mathrm{CaCO}_{3}$; calculated weight fraction of anatase ( $f$ (anatase)) was plotted against XRD-peak-area ratio of anatase and $\mathrm{CaCO}_{3}\left(R\left(\right.\right.$ anatase $\left.\left./ \mathrm{CaCO}_{3}\right)\right)$ to give straight line as shown in Figure 3. Least-squares fit of the straight line gives an equation of

$$
f(\text { anatase })=1.063 R\left(\text { anatase } / \mathrm{CaCO}_{3}\right)-0.091
$$

In the previous report, ${ }^{49}$ similar linear correlation was obtained for the mixture of anatase and rutile. However, by assuming a linear relation between the XRD peak intensity and fraction of given crystallites, the intercept should be zero. The discrepancy might be caused by the marked difference in the size of anatase and amorphous standard samples, though we could not obtain an anatase standard sample (without amorphous or hydrated $\mathrm{TiO}_{2}$ ) of crystallite size similar to amorphous $\mathrm{TiO}_{2}$ to confirm this. Anyway, practically the fraction of anatase in the samples could be evaluated from the XRD measurements. As shown in Figure 4, $f$ (anatase) evaluated by two methods, DSC and XRD

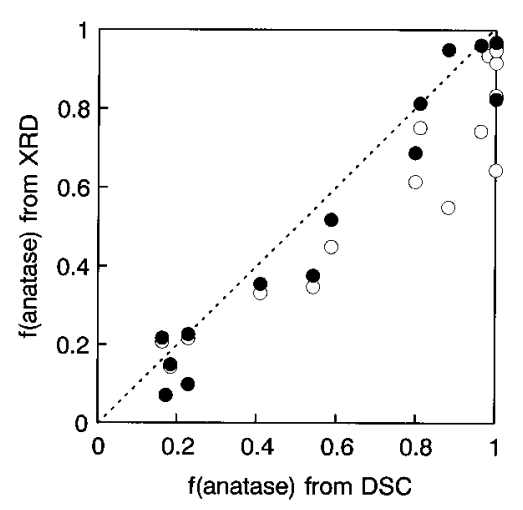

Figure 4. Comparison of the fraction of anatase crystallites ( $f$ (anatase)), obtained from XRD and DSC measurements, in the amorphous-anatase mixtures. Values of $f$ (anatase) from XRD without and with correction for smaller particle size (see Figure 6 and text) are plotted with open and closed circles, respectively, against those from DSC.

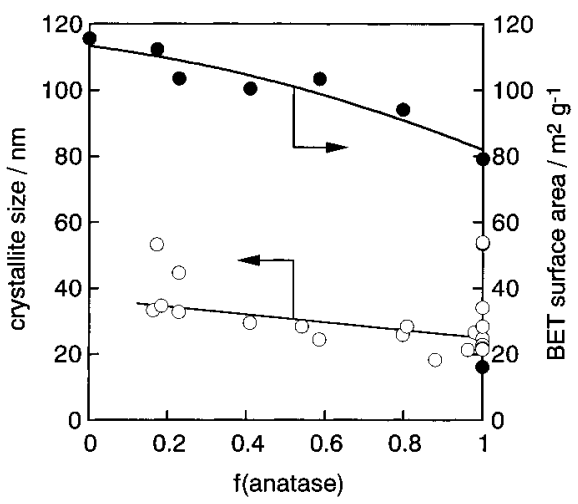

Figure 5. Plots of crystallite size of anatase and BET surface area of the amorphous-anatase mixtures as a function of fraction of anatase crystallites $(f($ anatase $))$.

(eqs 1 and 2), respectively), coincided roughly, supporting that disappearance of the exothermic peak of crystallization corresponds to appearance to anatase crystallites. The deviation from the line should be caused by the error in the calculation from the XRD data and will be discussed later.

From the XRD measurement, we could also obtain information on the size of anatase crystallites by using the Scherrer equation, ${ }^{18,50}$ as depicted in Figure 5 as a function of $f$ (anatase) (from DSC). It is clear from this figure that the crystallite size of anatase was almost constant, ca. $30 \mathrm{~nm}$, being independent of composition, while marked difference was seen when the crystallization was almost completed $(f($ anatase $)=1)$. These findings allow us to imagine that heat-induced transformation of amorphous to anatase is crystallization of each particle of amorphous $\mathrm{TiO}_{2}$ without sintering and growth of crystallites, while further calcination after complete crystallization makes the growth of anatase crystallites. Being consistent with the above-mentioned results, the change in the specific surface area of amorphous - anatase mixtures was not so marked (Figure 5); the BET surface area of as-received powder, ca. $115 \mathrm{~m}^{2} \mathrm{~g}^{-1}$, was reduced only $30 \%$ by complete crystallization. A difference in particle size of the as-received amorphous $\mathrm{TiO}_{2}(15-20 \mathrm{~nm})^{46}$ estimated by TEM and anatase crystallites at low $f$ (anatase) region (ca. $30 \mathrm{~nm}$ ) was seen. We have, at present, no reasonable interpretation for the difference.

The ratio of $f$ (anatase) values from XRD and DSC was plotted as a function of the crystallite size (Figure 6). A simple curve could be drawn to fit the data, except for the cases of small $f$ (anatase) $(<0.4)$ where crystallite-size measurements had large error due to the relatively small anatase peak. This curve is interpreted by assuming that the intensity of XRD peak becomes 


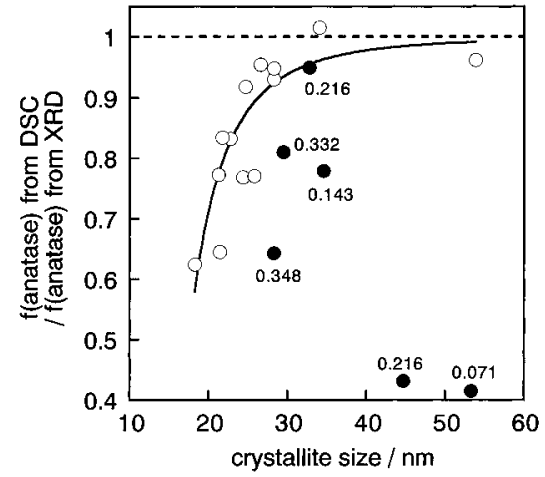

Figure 6. Ratio of $f$ (anatase) values obtained from XRD and DSC measurements as a function of anatase crystallite size. Open and closed circles show data for predominantly amorphous $(f($ anatase $)<0.4)$ and anatase, respectively. Numbers denote $f$ (anatase) obtained from DSC measurements.

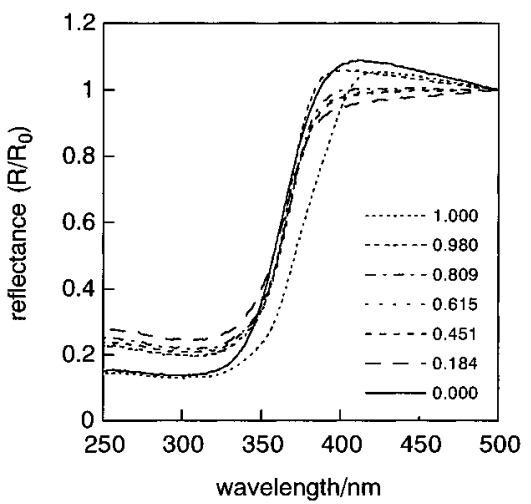

Figure 7. Reflection spectra of amorphous-anatase mixture in the ultraviolet and visible regions. Barium sulfate was used as a reference and reflectance $\left(R / R_{0}\right)$ was normalized at $500 \mathrm{~nm}$ to be 1 . Numbers denote $f$ (anatase).

smaller along with the decrease in crystallite size. These facts teach us the difficulty of measuring content of anatase crystallites of size smaller than $30 \mathrm{~nm}$ from XRD if the calibration line is drawn with larger crystallites of standard anatase sample (in this case the size of anatase crystallites of standard was $>200$ $\mathrm{nm}$ ). This problem is clarified first, to our knowledge, in this paper, since such small anatase crystallites sometimes contain amorphous and/or hydrated $\mathrm{TiO}_{2}$, which could not be measured quantitatively. On the basis of the results, the fraction of anatase, $f$ (anatase) evaluated from DSC measurement was used throughout this study. Values of $f$ (anatase) obtained from XRD and corrected with the solid line in Figure 6 was plotted in Figure 4. Improved linearity was seen as expected.

Figure 7 shows the reflection spectra of a part of the $\mathrm{TiO}_{2}$ samples used in this study. The absorption edge of amorphousanatase mixtures was constantly observed at ca. $380 \mathrm{~nm}$ in the $f$ (anatase) range from 0 to 0.98 . This indicates that both amorphous and anatase $\mathrm{TiO}_{2}$ particles of almost the same size have similar optical properties. Therefore, within the $f$ (anatase) range, we could expect that equal number of photons are absorbed by the suspensions of these amorphous-anatase samples. Further crystallization of anatase $(f$ (anatase $=1)$, i.e., the growth of anatase crystallites (54 nm, see Figure 5), shifted the spectrum to longer wavelength, i.e., the band gap was a little reduced. The absorption edge of ca. $400 \mathrm{~nm}$ corresponds to $3.1 \mathrm{eV}$, which coincides with the reported values. ${ }^{22,32,43}$

Photocatalytic Activities of the Amorphous-Anatase Mixture. Figure 8 shows the rate of photocatalytic reaction in three different systems evaluated from the slope of the almost linear time-course curves. In all the systems, the rate increased
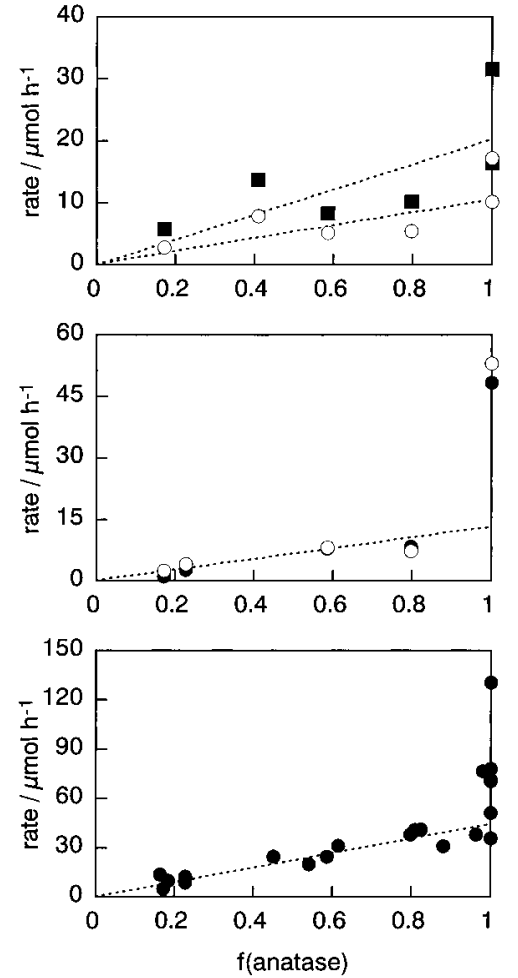

Figure 8. Rate of photocatalytic reactions by anatase-amorphous mixture in their deaerated aqueous suspensions: (upper) system A with bare $\mathrm{TiO}_{2}$ powder, silver sulfate, and 2-propanol under acidified conditions; (middle) system $\mathrm{B}$ with ex situ platinized $\mathrm{TiO}_{2}$ powder and 2-propanol under acidified conditions, and (lower) system $\mathrm{C}$ with in situ platinized $\mathrm{TiO}_{2}$ and 2-propanol. Closed circles, open circles, and squares refer to $\mathrm{H}_{2}$, acetone, and $\mathrm{Ag}$ metal, respectively.

linearly with $f$ (anatase) up to unity and markedly enhanced at $f($ anatase $)=1$. This fact suggests that only anatase crystallites, but not amorphous, induce the photocatalytic reactions and that the activity of anatase crystallites is improved further by the heat treatment. The latter finding will be discussed later.

In the reaction system A (Figure 8 upper), the molar amount of deposited Ag was approximately twice that of acetone as an oxidation product from 2-propanol, satisfying a stoichiometry of

$$
2 \mathrm{Ag}^{+}+\left(\mathrm{CH}_{3}\right)_{2} \mathrm{CHOH}=2 \mathrm{Ag}+\left(\mathrm{CH}_{3}\right)_{2} \mathrm{CO}+2 \mathrm{H}^{+}
$$

In the previous paper, we have shown that under such reaction conditions of low $\mathrm{pH}$, the rate of the photocatalytic reaction is governed by the reaction of a photogenerated positive hole $\left(\mathrm{h}^{+}\right)$ with 2-propanol, ${ }^{37}$ i.e., the overall rate $(r)$ is proportional to the amount of surface-adsorbed 2-propanol, but not $\mathrm{Ag}^{+}$. The following rate expression could be reasonably fit to the dependence of rate $(r)$ on the 2-propanol concentration ([2propanol $]_{\mathrm{ad}}$ ).

$$
r=I \phi k_{\mathrm{h}}[2-\text { propanol }]_{\mathrm{ad}} / k_{\mathrm{r}}
$$

where $I$ and $\phi$ are flux of photons absorbed by the photocatalyst and efficiency of production of $\mathrm{e}^{-}$and $\mathrm{h}^{+}$, and $k_{\mathrm{h}}$ and $k_{\mathrm{r}}$ are rate constants of reaction by $\mathrm{h}^{+}$and recombination of $\mathrm{e}^{-}$and $\mathrm{h}^{+}$, respectively. This equation is based on the idea that in a primary stage of photocatalytic reaction the photogenerated $\mathrm{e}^{-}-\mathrm{h}^{+}$pairs undergo recombination to give appreciable chemical reaction unless they react with the surface-adsorbed substrates. Under the acidic conditions, where surface hydroxyls are protonated to be positively charged, cations such as $\mathrm{Ag}^{+}$ are inhibited to be adsorbed and therefore they do not participate 
in the primary stage. The equation could reasonably imply the experimental results for polycrystalline $\mathrm{TiO}_{2}$ photocatalysts. ${ }^{37}$ Assuming that $I \phi$ is constant for the present amorphous-anatase samples (it seems to be reasonable to see their similar reflection spectra shown in Figure 7) and [2-propanol $]_{\mathrm{ad}}$ is proportional to the BET surface area, we can attribute the rate dependence in Figure 8 predominantly to the difference in the ratio of $S_{\mathrm{BET}}$ $k_{\mathrm{h}} / k_{\mathrm{r}}$ between amorphous and anatase particles (therefore, we would regard the ratio, estimated from the ratio of practical reaction rate to the surface area $\left(r / S_{\mathrm{BET}}\right)$ which was sometimes used in the studies of photocatalysis, ${ }^{27}$ as an intrinsic photocatalytic activity). Since, in the region of $f$ (anatase) $<1$, the BET surface area was almost constant or rather a little decreased, the increasing rate with $f$ (anatase) should be attributed to increasing ratio of $k_{\mathrm{h}} / k_{\mathrm{r}}$. The fact that the rate was negligible for amorphous $\mathrm{TiO}_{2}(f$ (anatase $\left.)=0\right)$ suggests the negligible $k_{\mathrm{h}} / k_{\mathrm{r}}$ ratio for amorphous particles.

Similar rate dependence was seen for the reaction systems B and $\mathrm{C}$ in which dehydrogenation of 2-propanol proceeds to yield equimolar amount of $\mathrm{H}_{2}$ and acetone (acetone was liberated in reaction $\mathrm{C}$, but was not measured quantitatively).

$$
\left(\mathrm{CH}_{3}\right)_{2} \mathrm{CHOH}=\left(\mathrm{CH}_{3}\right)_{2} \mathrm{CO}+\mathrm{H}_{2}
$$

It has been also clarified that the rate of this 2-propanol dehydrogenation is expressed by an equation similar to eq 4 for the platinized commercial $\mathrm{TiO}_{2}$ powders. ${ }^{43}$ Hence, similar interpretation that amorphous $\mathrm{TiO}_{2}$ is inactive also for the 2-propanol dehydrogenation may be plausible. It should be noted that the slope of linear relation for system B (Figure 8, middle) was almost equal to that for system A (Figure 8, upper); i.e., the limiting rate at $f($ anatase $)=1$ was almost the same in these systems. This is consistent with eq 4 which does not include the terms relating to reduction by $\mathrm{e}^{-}$; under the similar reaction conditions of same $\mathrm{pH},[2 \text {-propanol }]_{\mathrm{ad}}$ should be the same and the common reaction of 2-propanol with $\mathrm{h}^{+}$should predominate the overall reaction rates regardless of the different reduction processes.

The loaded platinum deposit acts as a site to reduce proton (or water) into $\mathrm{H}_{2}{ }^{51,52}$ It has been proved that for the photocatalytic 2-propanol dehydrogenation by small $\mathrm{TiO}_{2}$ particles (of a few dozens of $\mathrm{nm}$ ) at least one Pt deposit makes each $\mathrm{TiO}_{2}$ particle photoactive and the activity is constant or rather a little diminished by further loadings; i.e., the rate is almost constant regardless of the number of $\mathrm{Pt}$ deposits on particles so long as they have at least one Pt deposit. ${ }^{53}$ On the basis of these results, the photocatalytic activity of different kind of $\mathrm{TiO}_{2}$ powders should be compared with consideration of platinization, i.e., number of $\mathrm{Pt}$ deposits on each $\mathrm{TiO}_{2}$ particles. The above-mentioned fact that the rate of 2-propanol oxidation was almost the same regardless of the different reduction processes suggests that all the $\mathrm{TiO}_{2}$ (anatase) particles work as a photocatalyst; the impregnation followed by $\mathrm{H}_{2}$ reduction may produce $\mathrm{Pt}$ deposits which is enough for uniform platinization of the $\mathrm{TiO}_{2}$ particles.

On the other hand, the rate for system $\mathrm{C}$ was ca. 3 times faster than that of system B though the same 2-propanol dehydrogenation proceeded, maybe due to the difference in [2-propanol $]_{\text {ad }}$ in eq 4 since system $\mathrm{C}$ was neutral while system $\mathrm{B}$ was acidic. The actual [2-propanol $]_{\mathrm{ad}}$ could not be measured because the change in 2-propanol concentration by the adsorption in the dark was below the detectable limit. Anyway, the rate dependences on $f$ (anatase) in systems $\mathrm{B}$ and $\mathrm{C}$ are similar, showing that the different method of platinization gives no influence on the tendency of photocatalytic activity and, thereby,

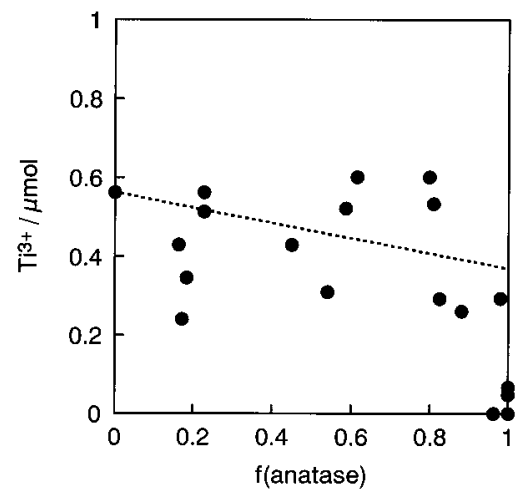

Figure 9. Amount of $\mathrm{Ti}^{3+}$ produced by the photoirradiation onto $\mathrm{TiO}_{2}$ suspensions in the presence of 2-propanol as a function of $f$ (anatase).

the rate shown in Figure 8 reflects the intrinsic photocatalytic activity of $\mathrm{TiO}_{2}$ particles.

Negligible Photocatalytic Activity of Amorphous $\mathrm{TiO}_{2}$. As described above, the present results are reasonably interpreted by assuming that the amorphous particle exhibits negligible photocatalytic activity for the reactions where 2-propanol is oxidized by $\mathrm{h}^{+}$and $\mathrm{Ag}^{+}$or $\mathrm{H}^{+}$is reduced by $\mathrm{e}^{-}$. Judging from the rate expression (eq 4), the negligible activity is accounted for by the negligible ratio of rate constants, $k_{\mathrm{h}} / k_{\mathrm{r}}$. We have, at present, no evidence to distinguish which rate constant governs the activity. However, we consider that large $k_{\mathrm{r}}$, i.e., facilitated $\mathrm{e}^{-}-\mathrm{h}^{+}$recombination in amorphous $\mathrm{TiO}_{2}$, cancels the photocatalytic activity, since it is probable that $k_{\mathrm{h}}$ reflects the structure of surface and/or adsorbed 2-propanol while $k_{\mathrm{r}}$ depends strongly on the bulk structure; the difference in effect of bulk structure to $k_{\mathrm{r}}$ between amorphous and anatase particles might be more extensive than that of surface structure to $k_{\mathrm{h}}$. Amorphous $\mathrm{TiO}_{2}$ must contain many imperfections, i.e., impurities, dangling bonds, or microvoids, which lead to electronic states in the band gap, and they behave as a recombination center for $\mathrm{e}^{-}-\mathrm{h}^{+} .54$ On the other hand, the surface structure depends on a shortrange order of bulk structure, which should be not so different between anatase and amorphous $\mathrm{TiO}_{2}$ particles; at least we could not expect the significant $k_{\mathrm{h}}$ difference which makes the $k_{\mathrm{h}} / k_{\mathrm{r}}$ ratio to be negligible.

Bickley and co-workers have reported that a commercial $\mathrm{TiO}_{2}$ (Degussa P-25) is a mixture of anatase crystallites with amorphous and rutile phases mainly on the basis of microscopic investigations. $^{22}$ They attributed the unusually high photocatalytic activity of the $\mathrm{TiO}_{2}$ particles to their complex structure and suggested that localized Anderson states of amorphous $\mathrm{TiO}_{2}$ may increase the lifetimes of $\mathrm{e}^{-}-\mathrm{h}^{+}$and thereby enhance the photocatalytic activity. This is in contrast with the present results, but the discrepancy may arise from the difference in the structure of $\mathrm{TiO}_{2}$ particles; the P-25 powder comprised coagulated anatase-amorphous and anatase-rutile particles, while in the present study the samples presumably consist of independent anatase and amorphous particles, as described in the preceding section.

Figure 9 shows the molar amount of $\mathrm{Ti}^{3+}$ formed during the photoirradiation in the presence of 2-propanol but in the absence of loaded Pt deposits. Since neither appropriate electron acceptor nor catalyst (such as $\mathrm{Pt}$ for $\mathrm{H}_{2}$ evolution) is present in the reaction system, $\mathrm{TiO}_{2}$ itself is reduced by $\mathrm{e}^{-}$; the suspension turned gray or blue gray by the photoirradiation. This $\mathrm{Ti}^{3+}$ formation is caused by the trapping of $\mathrm{e}^{-}$at the defects ${ }^{29,55}$ along with the oxidation of 2-propanol with $\mathrm{h}^{+}$and its amount seems to be an indication of oxygen anion $\left(\mathrm{O}^{2-}\right)$ vacancy or $\mathrm{O}^{2-}$ weakly bonded to $\mathrm{Ti}^{4+}$. Since both $\mathrm{Ti}^{3+}$ and $\mathrm{MV}^{\bullet+}$ are highly reactive toward $\mathrm{O}_{2}$ in the atmosphere and are oxidized quickly, 


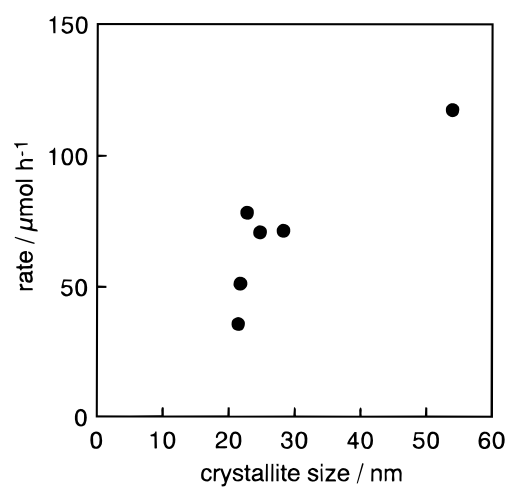

Figure 10. Rate of photocatalytic $\mathrm{H}_{2}$ evolution by completely crystallized anatase $\mathrm{TiO}_{2}$ suspended in deaerated aqueous solution of 2-propanol as a function of anatase crystallite size.

i.e., they are readily quenched by small amount of $\mathrm{O}_{2}$ contaminant during the measurements, large experimental error should be included in the results shown in Figure 9. However, a tendency is seen that appreciable amount of $\mathrm{Ti}^{3+}$ was formed in partly crystallized samples $(f$ (anatase) $<1)$ but was negligible when completely crystallized $(f($ anatase $)=1)$. It seems that the $\mathrm{Ti}^{3+}$ amount is roughly proportional to the BET surface area depicted in Figure 5, and therefore $\mathrm{Ti}^{3+}$ species might be located on the surface of both amorphous and anatase particles; i.e., the $\mathrm{Ti}^{3+}$ amount should be a measure of the common $\mathrm{e}^{-}-\mathrm{h}^{+}$ recombination site on the surface. The fact that even the $\mathrm{TiO}_{2}$ particles consisting of predominantly anatase (high $f$ (anatase) but not unity) which showed relatively high activity gave appreciable amount of $\mathrm{Ti}^{3+}$ suggests that not only the surface defect, i.e., recombination center, detected as $\mathrm{Ti}^{3+}$, but also bulk defect(s) accelerates the recombination leading to the negligible activity of amorphous $\mathrm{TiO}_{2}$.

Photocatalytic Activity of Anatase Crystallites. As depicted in Figure 8, a large difference in the photocatalytic activity of anatase $\mathrm{TiO}_{2}$ powders $(f($ anatase $)=1)$ was seen. This is in accord with the fact that many anatase $\mathrm{TiO}_{2}$ powders available commercially or prepared in laboratories show extensively different photocatalytic activity; i.e., the crystal phase is not a sole decisive factor of activity. The rate for system $\mathrm{C}$ is plotted in Figure 10 as a function of anatase crystallite size. It seems that the rate of $\mathrm{H}_{2}$ production, i.e., photocatalytic activity, in system $\mathrm{C}$ increased with the growth of anatase crystallites, though we could not obtain a quantitative interpretation and conclusion from this scattered plot. The data for smaller size of anatase could not be obtained since the starting amorphous $\mathrm{TiO}_{2}$ consist of $15-30 \mathrm{~nm}$ particles. Furthermore, preparation of mid-sized $(40-50 \mathrm{~nm})$ particles by controlling the calcination conditions was rather difficult and we have not succeeded. Anyway, the tendency is consistent with the assumption that $k_{\mathrm{r}}$ decreasing upon calcination overcomes the negative effect by decreased BET surface area leading to smaller [2-propanol $]_{\mathrm{ad}}$ to result in the higher photocatalytic activity.

Although the surface defects, detected as $\mathrm{Ti}^{3+}$, disappeared almost completely by the crystallization, the bulk defects might be present. The annealing at higher temperature (for $\mathrm{TiO}_{2}$ of $54 \mathrm{~nm}$ size: $973 \mathrm{~K}$ ) leads to its disappearance along with the crystal growth. As also described in the preceding section, quality and quantity of the bulk crystal defects are important to discuss the photocatalytic activity of amorphous, as well as crystalline, semiconductor materials. The recent report by Colombo and Bowman pointed out on the basis of the results of femtosecond diffuse reflectance spectroscopy ${ }^{56-58}$ that two traps, surface and interstitial (bulk), participate in the recombination kinetics of $\mathrm{TiO}_{2}$ powders.

\section{Conclusion}

The photocatalytic activity of amorphous $\mathrm{TiO}_{2}$ (not hydrated $\mathrm{TiO}_{2}$ or titanium(IV) hydroxide) is clarified to be negligible in some deaerated suspensions, while anatase crystallites in similar particle size of ca. $30 \mathrm{~nm}$ show appreciable photocatalytic activity. The negligibly low activity of amorphous $\mathrm{TiO}_{2}$ is attributable to the facilitated recombination of $\mathrm{e}^{-}$and $\mathrm{h}^{+}$at the traps on the surface and in the bulk of the particles. The predominant participation of the latter traps is suggested, but their qualitative and quantitative evaluation has not been achieved. These results give essential and important information for the design and synthesis of highly active semiconductor photocatalyst. Time-resolved studies on the recombination kinetics in these $\mathrm{TiO}_{2}$ particles are in progress.

Note Added in Proof. One of the referees pointed out the importance of comparison of photocatalytic activity which is normalized with unit surface area. However, at least in this study, the BET surface area was almost constant within $f$ (anatase) range $<1$, and thereby we could conclude that amorphous $\mathrm{TiO}_{2}$ has negligible photocatalytic activity. The referee also suggested the difficulty in estimation of photoabsorption characteristics. Previous reports have demonstrated the more sophisticated procedure, e.g.: Palmisano, L.; Augugliaro, V.; Compostrini, R.; Shiavello, M. J. Catal. 1993, 143, 149. In this paper, however, simple procedures were employed for convenience to evaluate the photocatalytic activity.

Acknowledgment. The authors thank Dr. Yukihiro Tsuchida (Idemitsu Kosan Co., Ltd.) for the supply of amorphous $\mathrm{TiO}_{2}$ samples. Professor Yoshiya Kera, Dr. Hiroshi Kominami, and Mr. Jun-ichi Kato (Kinki University) are gratefully acknowledged for the permission to use the reflection spectrometer and for the help in measurements. The authors are indebted to Messrs. Satoshi Kusakabe and Takayuki Yako (Kyoto University) for their help in $\mathrm{Ti}^{3+}$ measurements and data processing, respectively. Financial support by Foundation of Space Science Promotion and Kansai Research Foundation for Technology Promotion is acknowledged. This investigation was partly supported by a Grant-in-Aid from the Ministry of Education, Science, Sports, and Culture of Japan.

\section{References and Notes}

(1) Bard, A. J. Science 1980, 207, 139.

(2) Bard, A. J. J. Phys. Chem. 1982, 86, 172.

(3) Inoue, T.; Fujishima, A.; Konishi, S.; Honda, H. Nature 1979, 277, 633.

(4) Henglein, A.; Gutierrez; Fisher, C.-H. Ber. Bunsenges. Phys. Chem. 1984, 88,170

(5) Cook, R. L.; MacDuff, R. C.; Sammells, A. F. J. Electrochem. Soc. 1988, 135, 3069.

(6) Irvine, J. T. Solar Energy 1990, 45, 27.

(7) Inoue, H.; Kubo, Y.; Yoneyama, H. J. Chem. Soc., Faraday Trans. 1991, 87, 553.

(8) Ishitani, O.; Inoue, T.; Suzuki, K.; Ibusuki, T. J. Photochem. Photobiol., A. Chem. 1993, 72, 269.

(9) Fox, M. A.; Dulay, M. T. Chem. Rev. 1993, 93, 341.

(10) Kisch, H. J. Prakt. Chem. 1994, 336, 635.

(11) Ohtani, B. In Trends in Photochemistry and Photobiology; Council of Scientific Information, Ed.; Research Trends: Trivandrum, India, 1994; Vol. 3, p 531.

(12) Mills, A.; Davies, R. H.; Worsley, D. Chem. Soc. Rev. 1993, 417.

(13) Kamat, P. V. Chem. Rev. 1993, 93, 267.

(14) Hoffmann, M. R.; Martin, S. T.; Choi, W.; Bahnemann, D. W. Chem. Rev. 1995, 95, 69.

(15) Photocatalysis: Fundamentals and Applications; Serpone, N., Pelizzetti, E., Eds.; John Wiley \& Sons: New York, 1989. 3659.

(16) Mills, A.; Porter, G. J. Chem. Soc., Faraday Trans. 1 1982, 78,

(17) Yamaguti, K.; Sato, S. Nippon Kagaku Kaishi 1984, 258.

(18) Nishimoto, S.-i.; Ohtani, B.; Sakamoto, A.; Kagiya, T., Nippon Kagaku Kaishi 1984, 246. 
(19) Toyuki, H.; Itami, M.; Hatta, K.; Kawamoto, Y. Nippon Kagaku Kaishi 1984, 1363.

(20) Nishimoto, S.-i.; Ohtani, B.; Kajiwara, H.; Kagiya, T. J. Chem. Soc., Faraday Trans. 1 1985, 81, 61.

(21) Matsumura, M.; Tsubomura, H. Ryusan to Kogyo 1987, 40, 1.

(22) Bickley, R. I.; Gonzalez-Carreno, T.; Lees, J. S.; Palmisano, L.; Tilley, R. J. D. J. Solid State Chem. 1991, 92, 178.

(23) Ohtani, B.; Zhang, S.-W.; Nishimoto, S.-i.; Kagiya, T. J. Photochem. Photobiol., A: Chem. 1992, 64, 223. 50 .

(24) Sakata, T.; Kawai, T.; Hashimoto, K. Chem. Phys. Lett. 1982, 88,

(25) Ohtani, B.; Handa, J.-i.; Nishimoto, S.-i.; Kagiya, T. Chem. Phys. Lett. 1985, 120, 292.

(26) Sclafani, A.; Palmisano, L.; Schiavello, M. J. Phys. Chem. 1990, $94,829$.

(27) Tanaka, K.; V.Capule, M. F.; Hisanaga, T. Chem. Phys. Lett. 1991, 187,73 .

(28) Oosawa, Y.; Grätzel, M. J. Chem. Soc., Chem. Commun. 1984, 1629.

(29) Ohtani, B.; Okugawa, Y.; Nishimoto, S.-i.; Kagiya, T. J. Phys. Chem. 1987, 91, 3550.

(30) Oosawa, Y.; Grätzel, M. J. Chem. Soc., Faraday Trans. 1 1988, $84,197$.

(31) Kraeutler, B.; Bard, A. J. J. Am. Chem. Soc. 1978, 100, 5985.

(32) Rao, M. V.; Rajeswar, K.; Pai Verneker, V. R.; DuBow, J. J. Phys.

Chem. 1980, 84, 1987.

(33) Davidson, R. S.; Morrison, C. L.; Abraham, J. J. Photochem. 1984, $24,27$.

(34) Harada, H.; Hidaka, H.; Ueda, T. Res. Bull. Meisei Univ. 1985, 21,45 .

(35) Harada, H.; Kanno, H.; Ueda, T. Denki Kagaku oyobi Kogyo Butsuri Kagaku 1985, 53, 736.

(36) Nishimoto, S.-i.; Ohtani, B.; Kajiwara, H.; Kagiya, T. J. Chem. Soc., Faraday Trans. 1 1983, 79, 2685.

(37) Ohtani, B.; Kakimoto, M.; Nishimoto, S.-i.; Kagiya, T. J. Phys. Chem. 1988, 92, 5773.

(38) Ohtani, B.; Nishimoto, S.-i. J. Phys. Chem. 1993, 97, 920.
2,7 .

(40) Kominami, H.; Matsuura, T.; Iwai, K.; Ohtani, B.; Nishimoto, S.i.; Kera, Y. Chem. Lett. 1995, 693.

(41) Ohtani, B.; Iwai, K.; Kominami, H.; Matsuura, T.; Kera, Y.; Nishimoto, S.-i. Chem. Phys. Lett. 1995, 242, 315.

(42) Kominami, H.; Kato, J.-i.; Takada, Y.; Ohtani, B.; Inoue, M.; Inui, T.; Kera, Y. Catal. Lett., in press.

(43) Ohtani, B.; Nishimoto, S.-i.; Kagiya, T. J. Chem. Soc., Faraday Trans. 1 1985, 81, 2467.

(44) Ohtani, B.; Kakimoto, M.; Nishimoto, S.-i.; Kagiya, T. J. Photochem. Photobiol., A: Chem. 1993, 70, 265.

(45) Watanabe, T.; Honda, K. J. Phys. Chem. 1982, 86, 2617.

(46) Idemitsu Co. Ltd. IDEMITSU Ultra Fine Particles of Titanium Dioxide; Idemitsu Co. Ltd., 1988.

(47) Encyclopedia of Chemical Technology, 2nd ed.; Kirk and Othmer, Eds.; Wiley-Interscience: New York, 1969; Vol. 20, pp 390.

(48) Grigorovici, R.; Manaila, R. Nature 1970, 226, 143.

(49) Spurr, R. A.; Myers, H. Anal. Chem. 1957, 29, 760.

(50) Klug, H.; Alexander, L. E. X-ray Diffraction Procedures, 2nd ed.; John Wiley and Sons, Inc.: New York, 1974; p 618.

(51) Nakabayashi, S.; Fujishima, A.; Honda, K. Chem. Phys. Lett. 1983, $102,464$.

(52) Baba, R.; Nakabayashi, S.; Fujishima, A.; Honda, K. J. Phys. Chem. 1985, 89, 1902 .

(53) Ohtani, B.; Iwai, K.; Nishimoto, S.-i.; Sato, S. J. Phys. Chem. B, in press.

(54) Mott, N. F.; Davis, E. A. Electronic Processes in Non-crystalline Materials, 2nd ed.; Oxford University Press: Oxford, U.K., 1979; p 210

(55) Buss, A. D.; Malati, M. A. J. Oil. Colour Chem. Assoc. 1976, 59, 369.

(56) Colombo, D. P., Jr.; Bowman, R. M. J. Phys. Chem. 1995, 99, 11752.

(57) Colombo, D. P., Jr.; Roussel, K. A.; Saeh, J.; Skinner, D. E.; Cavaleri, J. J.; Bowman, R. M. Chem. Phys. Lett. 1995, 232, 207.

(58) Colombo, D. P., Jr.; Bowman, R. M. J. Chem. Phys. 1996, 100, 18445 